\title{
The Impact of Cognitive (Reflectivity/Impulsivity) on Tertiary EFL Learners' Syntactic Complexity in Descriptive Writing
}

\author{
Ayu Yuniasari ${ }^{1 *}$, Zainuddin ${ }^{2}$ \\ ${ }^{1}$ Faculty of Cultural Sciences, Universitas Sumatera Utara, Indonesia \\ ${ }^{2}$ Faculty of Languages and Arts, Universitas Negeri Medan, Indonesia
}

Corresponding Author: Ayu Yuniasari, E-mail: ayuyuniasari58@gmail.com

\section{ARTICLE INFO}

Article history

Received: October 17, 2018

Accepted: December 21, 2018

Published: February 28, 2019

Volume: 10 Issue: 1

Advance access: January 2019

Conflicts of interest: None

Funding: None

\section{Key words:}

Cognitive,

Reflective,

Impulsive,

Syntax,

Writing

\begin{abstract}
The purpose of this study was to investigate the probable effects of cognitive in linguistics properties of descriptive writing. The cognitive was studied on reflectivity and impulsivity in which students were categorized in to two groups. The linguistics properties of the learners' descriptive writings were examined through syntactic complexity under syntax studies umbrella. The participants were selected from systematic random sampling technique and by applying the personality test subjected degree of cognitive level from Eysenck Personality Questionnaire (30 from the most reflective learners and 30 from the most impulsive learners). The selected participants were asked to write descriptive essay about person. Syntactic complexity (simple, compound, complex and compound-complex) was calculated from each of learners' writing and the significant difference between two groups were analyzed by employing the independent sample $t$ - test in SPSS version 21. The result shows that there were differences between reflective and impulsive learners in producing syntactic complexity in descriptive writing. Even though, there were differences on syntactic complexity, the assumption of teachers on, impulsive learners are better than reflective students, does not suit to the linguistics properties competencies and performances especially on syntactic complexity of the descriptive writing because both of them had their own superiority in syntactic complexity.
\end{abstract}

\section{INTRODUCTION}

\section{Background of Study}

Writing is one of the four skills in teaching and learning English. Literally, writing skill is very important since it is an effective medium for communication. Moreover, writing is a required skill to be mastered by EFL and native English learners because it gives a freedom space for students to express their ideas in a peace of papers (Sharples, 1999).

Practically, most of the students feel that writing skill is the most difficult skill compared to other skills such as speaking, listening and reading because it requires detail study and more practice to improve the students' achievements that is why writing is not only a product but also a process (Oshima and Hogue, 1999).

Furthermore, the characteristics of written language from the writer's viewpoint are six points and one of those is complexity (Brown, 2007). Complexity here means writes must learn how to remove redundancy, how to combine sentences, how to make references to other elements in a text, how to create syntactic and lexical variety, and much more. Additionally, Brown (1994) in evaluating or assess students' writings there are six categories as the basis for the evaluation.
They are content, organization, discourse, syntax, vocabulary and mechanism.

Theoretically, base on the characteristics and evaluation checklist of the writing syntax is one of the very important linguistics properties. Therefore, it is very crucial to investigate on how the students compose the sentences in writing because different students might have different way of combining the sentences in writing.

In accordance with the way of students in combining the sentences, many scholars have already agreed that the characteristics of the learners affect the learners' performances and competencies in writing. According to Vaezi (2012) there are three, which affects students' performances and competencies in writing. They are affective, cognitive and biology. Hence, this study is very important to answer the teachers' assumption, which stated that reflective learners are better than impulsive learners in learning English as a Foreign Language.

\section{Objectives of Study}

Therefore, this study was aimed at investigating on how the different cognitive (reflective and impulsive) students write 
sentences in their descriptive writing as descriptive writing is one of the genre in writing composition that needs to be mastered by students in Indonesian English curriculum for tertiary students $(K B S B, 2008)$. The main focus in this study was the complexity of the sentence (syntax) in students' descriptive writing.

\section{Research Question}

In accordance with the objective of the study, the research question is formulated as follow:

1) Is there any significant difference between reflective and impulsive tertiary EFL learners in producing syntactic complexity in descriptive writing?

\section{LITERATURE REVIEW}

\section{Cognitive}

In cognitive psychology, a complete review of study has designated that every person has significant personal differences in the cognitive, which she/he applies in decision making, critical thinking and problem solving (Robertson, 1985).

Literally, there are many definitions of cognitive. First, Witkin and Goodenaough (1981) suggested that cognitive has natural features; formal, pervasiveness, consistency, polarity and value neutral. It means that cognitive styles are focusing on the form rather than the cognitive activity content. Moreover, another definition of cognitive is as individual's characteristics and constant approach to systemizing and sorting out information (Tennant, 1988).

Different aspects of cognitive styles are emphasized by different scholars. Accordingly, there are several denominations of literature in this field. Brown (2000) proposed left and right brain functioning, independence, tolerance of ambiguity, auditory and visual styles, reflective and impulsive as part of the cognitive styles. But, from all the cognitive styles, reflective and impulsive are the most studied in English language teaching and learning.

\section{Reflectivity and Impulsivity}

Historically, studies about reflectivity and impulsivity were started in the early 1960 s by numerous researchers. Kagan (1996) proposed the definition of these variables as a conceptual tempo, or decision time variable. Impulsive gives fast responds and report with little focus on accuracy and reflective gives slow respond and report with more focus on accuracy. Furthermore, Brown (2000) defined reflective and impulsive as the level to which, in the cognitive domain, a person tends to make either a quick guess (impulsive) at an answer to a problem or a slower (reflective) decision.

Based on the two definitions, it can be simplified that impulsive learner is a learner who can give quick respond or answer to a question with less concern on accuracy. On the other hand, the reflective learner is the learner who gives slow respond or answer to a questions with more focus on the accuracy of the answer.

\section{Syntactic Complexity}

Syntax is one of the linguistic properties. Prasad (2012) defines syntax as "the way of words and phrases are combined to form sentences in a language". In addition, literally, the word "syntax" consists of two word-elements, syn-, the latinized form of Greek preposition "sun" which means together and-tax, derived from a Greek root, which means to put in order. The meaning of syntax is, thus, putting things together in an orderly manner. In brief, it is the grammar of sentences, a study of the ways in which words can be strung together to form acceptable sentences (Prasad, 2012).

Syntax complexity is one of the three important elements in writing development in addition to fluency and accuracy (Hunt, 1970). Even though many studies have examined syntactic complexity in the pas, measures used to examine the syntactic complexity have been still a challenge for researchers because literally, syntax complexity is a broad study. There are many elements included in syntax complexity such as word, phrase, clauses, sentence types, and T-unit. Although syntactic complexity is a wide study, it is normally categorized in to six (6) clusters. They are T-units, sentences, clauses, phrases, words, and combined measures (Jagaiah, 2016).

Since the syntactic complexity is a huge topic, the category of the syntactic complexity in this recent study is narrowed down to sentence types in a written product.

Different language may have different sentence types but in English there are four types of sentences according to grammatical structure of the sentences: 1) simple sentence, 2) compound sentence, 3) complex sentence and 4) compound-complex sentence. More details about each type of sentences is presented as follows.

\section{Simple sentence}

It contains only one subject and one predicate. Even though the sentence is very long but if it has only one subject and one predicate, it is still categorized as simple sentence. For instance: the third semester students is discussing in classroom.
the third semester students
= Subject
is discussing
$=$ Predicate
in classroom
= Complement

\section{Compound sentence}

It contains two or more independent simple sentences. Normally, the sentences are combined by conjunction such as and, or, therefore, but, hence, thus, so that and etcetera. For instance: America and Japan are considered as developed countries but Indonesia and Brunei Darussalam are considered as developing countries.
America and Japan
are considered as
developed countries
$=$ Subject
but
$=$ Predicate
$=$ Object
$=$ Conjunction
Indonesia and Brunei Darussalam
$=$ Subject
are considered as
$=$ Predicate
developing countries 
From this sentence, it can be seen that before and after the conjunction there is independent simple sentence. In addition, the position of the conjunction normally should be in between.

\section{Complex sentence}

It contains one independent clause and one or more dependent clauses. The main idea or sentence is put as main clause and the subordinate is put as subordinate clause. Normally, the subordinate clause is from the view of time, cause, effect, purpose, requirements, and etcetera such as although, even though, because, if, so that, while, when, after, before, and etcetera. For instance: although today is raining, Andi is still going to school.

although today is raining = Dependent clauses

Andi is still going to school= Independent Clause

\section{Coumpund-complex sentence}

It contains two independent clauses and one or more dependent clauses. For instance: we have gone home but they have been still working because their task has not been finished yet.

we have gone home

\section{but}

they have been still working

clause

their task has not been finished yet

$$
\begin{aligned}
= & \text { Independent } \\
& \text { clause } \\
= & \text { conjunction } \\
= & \text { independent } \\
= & \text { dependent } \\
& \text { clause }
\end{aligned}
$$

According to the explanation above, the four types of sentences base on the grammatical structure in Indonesian Language are similar with sentence type in English language. Therefore, in students' language written product must contain these types of sentences. Related to the students' personality traits, each student may have different way of composing a text. On that reason, syntactic complexity needs to be investigated in different personality students' written product.

\section{Relation of Cognitive and Syntactic Complexity}

Logically, there is a relation of cognitive style (reflective and impulsive) with syntactic complexity. As reflective is defined as a fast respond with less accuracy (Brown, 2000; Kagan, 1996), they might more write the simple sentence since they will not think of the syntactic accuracy and complexity in giving composing the sentences. On the other hand, as impulsive is defined as the slow respond with more focus on accuracy (Brown, 2000; Kagan, 1996), the impulsive learners might write more complex sentences because they tend to give a complex answer or explanation on their writing. Therefore, to prove this assumption, that was why this study needed to be conducted.

\section{Previous Study on Cognitive and Syntactic Complexity}

There are many studies, which have been done by numerous scholars on the correlation of individual characteristics with language skills competencies and performances. For example, Sanjaya, Azman, and Sumarsih (2015) stated that there was a significant difference between extrovert and introvert in writing skill. Moreover, Zainuddin (2016) claimed that introvert students outperformed the extrovert students in the test of syntax ability in descriptive essay. But, only few studies on the correlation of cognitive styles (reflective/impulsive) with syntactic complexity. For example, Vaezi (2012) has done a descriptive analysis on learner characteristics and syntactic and lexical complexity of written product. In his study, he investigated 30 essays from impulsive students and 30 essays from reflective students. Then, he found that there was no significant different between reflective and impulsive students in constructing the syntactic complexity of the sentences in writing.

\section{RESEARCH METHOD}

\section{Research Participants}

This research was administered to 30 impulsive and 30 reflective Indonesian language learners in the Faculty of Languages and Arts, Universitas Negeri Medan, Indonesia. The participants' ages are from 20 to 21 year-old. By using MBTI questionnaire, the participants were purposively selected from 72 extroversions and 44 introversions based on their scores on personality traits questionnaire.

\section{Material}

Myers Briggs Types Indicator (MBTI) questionnaire: Myers $\&$ Briggs (1998) developed this questionnaire. There are 70 questions in this questionnaire. The questions, which examine the respondent's impulsive or reflective (I/R) personality, are 10 questions only. Even though the items for I/R are only ten (10) questions, they should not be taken out from complete questionnaire since this questionnaire was integrated and the rest of the questions actually only to measure what types of I/R the participants are. In addition, quite numerous scholars such as Wakamoto, (2007), Marefat (2006), Carrell (1995) used this questionnaire to classify the personality types of participants in their research on correlation of personality with language skills.

Writing task: A writing task was administered to reflective and impulsive groups. The task was asking the participants to write a descriptive essay in English about 220 to 250 words. The topic of the task was about a place. The question is as following:

\footnotetext{
"Write a descriptive essay about your university in about 220 to 250 words!"
}

Thus, the task was only one question. For the information, a descriptive essay is one of the genres in writing skill that have to be mastered by the Indonesian language learners in Indonesia.

\section{Technique of Analyzing the Data}

The sentence types in each essay were grouped and counted manually. Then, the number of each type of sentences on ex- 
trovert and introvert groups' essays was listed and tabulated by using independent sample t-test in Statistical Package for Social Science (SPSS) version 2.1 to find out the significant difference between extrovert and introvert groups in constructing the sentences in written product.

\section{RESULT AND DISCUSSION}

From 30-impulsive and 30-reflective language learners' written products, the number of each type of sentences were collected and tabulated by using independent sample t-test to compare the syntactical complexity between impulsive and reflective learners. Hence, the comparison is shown as follow:

Table 1 shows the value of means, standard deviation and standard error of the mean for the two groups on four (4) types of sentences according syntactical complexity. The mean score of the reflective learners on Simple Sen-

Table 1. The Comparison of reflective and impulsive learners' syntactical complexity

\begin{tabular}{lcccc}
\hline Character & N & Mean & $\begin{array}{c}\text { Standard } \\
\text { deviation }\end{array}$ & $\begin{array}{c}\text { Standard } \\
\text { error mean }\end{array}$ \\
\hline SS & & & & \\
$\quad$ Reflective & 30 & 15.47 & 1.12 & 0.20 \\
$\quad$ Impulsive & 30 & 5.00 & 0.72 & 0.11 \\
CpdS & & & & \\
Reflective & 30 & 5.00 & 0.70 & 0.13 \\
Impulsive & 30 & 9.20 & 1.10 & 0.20 \\
CpxS & & & & \\
Reflective & 30 & 8.21 & 1.39 & 0.25 \\
Impulsive & 30 & 7.41 & 1.46 & 0.27 \\
CCS & & & & \\
Reflective & 30 & 0.80 & 0.51 & 0.09 \\
Impulsive & 30 & 5.20 & 0.92 & 0.17 \\
\hline
\end{tabular}

tence (SS) was 10.47 higher than the impulsive learners. In contrast, on Compound Sentence (CpdS) the reflective learners outperformed the impulsive learners about 4.20 points. Meanwhile, on the Complex Sentence (CpxS) there is no much difference between reflective and impulsive group because impulsive learners was only lower 0.80 points than reflective group. But, on Compound Complex Sentence the impulsive group was much higher than reflective, which was 4.40 points. Overall, there were differences between impulsive and reflective groups in terms of syntactical complexity in written product. Therefore, to examine the significant difference between reflective and impulsive groups in syntactical complexity, the data were tabulated and computed by using independent sample t-test. The result of the test is presented in the following Table 2.

An independent sample t-test was computed in SPSS version 21 to find out the difference between impulsive and reflective in terms of syntactical complexity. The test was found that Levene's test for quality of variance was found to be examined for the present analysis, for Simple Sentence (SS) $F=12.69, \mathrm{p} \leq .05$, for Compound Sentence (CpdS) $\mathrm{F}=8.82, \mathrm{p} \leq 0.05$, for Complex Sentence (CpxS) $\mathrm{F}=1.28, \mathrm{p} \geq .05$, and for Compound Complex Sentence (CCS) $\mathrm{F}=32.77, \mathrm{p} \leq .05$. Based on this result, it was found that a t statistic for SS, CpdS and CCS assuming homogeneity of variance was computed but for $\mathrm{CpxS}$ was not variance.

Moreover, this test was found to be statistically significant for SS t $(58)=46.255, \mathrm{p} \leq .05$, for CpdS t $(58)$ $=-17.883, \mathrm{p} \leq .05$, for $\operatorname{CCS} \mathrm{t}(58)=-22.501, \mathrm{p} \leq .05$. The results indicated that there was significant difference between impulsive and reflective group in terms of sentence types, which are on Simple Sentence, Compound Sentence and Compound Complex Sentence. But for CpxS t (58) =.724, $\mathrm{p} \geq .05$, the result indicated that there was no significant difference between impulsive and reflective groups in terms of Complex Sentence $(\mathrm{CpxS})$ in written product. It means

Table 2. Result of independent sample t-test

\begin{tabular}{|c|c|c|c|c|c|}
\hline & \multicolumn{2}{|c|}{$\begin{array}{c}\text { Levene's test for } \\
\text { equality of variances }\end{array}$} & \multicolumn{3}{|c|}{ t-test for equality of means } \\
\hline & $\mathbf{F}$ & Sig. & $\mathbf{t}$ & df & Sig. (2-tailed) \\
\hline \multicolumn{6}{|l|}{ SS } \\
\hline Equal variances assumed & 12.69 & 0.002 & 46.255 & 58 & 0.001 \\
\hline Equal variances not assumed & & & 46.255 & 49.948 & 0.001 \\
\hline \multicolumn{6}{|l|}{ CpdS } \\
\hline Equal variances assumed & 8.82 & 0.003 & -17.883 & 58 & 0.001 \\
\hline Equal variances not assumed & & & -17.883 & 48.473 & 0.001 \\
\hline \multicolumn{6}{|l|}{ CpdS } \\
\hline Equal variances assumed & 1.275 & 0.264 & 0.724 & 58 & 0.473 \\
\hline Equal variances not assumed & & & 0.724 & 57.857 & 0.473 \\
\hline \multicolumn{6}{|l|}{$\mathrm{CCS}$} \\
\hline Equal variances assumed & 32.77 & 0.001 & -22.501 & 57 & 0.002 \\
\hline Equal variances not assumed & & & -22.501 & 45.011 & 0.002 \\
\hline
\end{tabular}


they have similar number of this type of sentences in their written product.

In accordance with the results and discussion, many agree with Sanjaya, Azman, and Sumarsih (2015). They stated that there was a significant difference between personalities in writing skill. In addition, Jagaiah (2017) concluded that syntactic complexity has a strong relation to writing quality. It means that the more complex of the sentences in written product, the higher the quality of the writing itself. Since the finding of this current study stated that reflective learners wrote more on Simple Sentence (SS) and less on Compound Complex Sentences (CCS). Teacher should encourage and teach them to write more CCS until they reach the proportion amount of CCS in their writings. On the other hand, the impulsive wrote more on Compound Sentences and Compound Complex Sentences and less Simple Sentence in their writings. Teacher should control and monitor them not to write sentences very long in order for reader to understand the content. In so doing, teachers have to encourage the students to write the proportion syntactical complexity in their writings.

\section{CONCLUSION}

From the result and discussion, it can be concluded that there is a difference between reflective and impulsive language learners in writing an essay particularly in constructing the sentences. This might happen because their characteristics automatically control them to do so, but, even though they have natural difference, both of them still have ability to improve their writing achievements. The teachers should monitor, guide and train them on how to write variety of sentences in their essay.

\section{REFERENCES}

Brown, H.D. (1994). Principles of language learning and teaching ( $3^{\text {rd }}$ edition).

Englewood Cliffs, NJ: Prentice Hall Regents.

Brown, H.D. (2000). Principles of language learning and teaching ( $4^{\text {th }}$ edition). New York: Pearson Longman.

Brown, H. D. (2007). Teaching by Principles; An Interactive Approach to Language Pedagogy. Third Edition. New York: Pearson Longman.

Carrell, P. L. (1995). The effects of writers' personalities and raters' personalities on the holistic evaluation of writing. Assessing Writing, 2, 153-190.
Hunt, K.W. (1970). Syntactic maturity in school children and adults. Monographs of the Society for Research in Child Development, 35 (1), 1- 61.

Jagaiah, T. (2016). Syntactic complexity measures: Variation by genre, grade-level, and students writing abilities. Unpublished manuscript.

Kagan, J. (1996). Reflection- impulsivity: the generality and dynamics of conceptual tempo. Journal of Abnormal Psychology, 71, 17-24. http://dx.doi.org/10.1037/ h0022886.

Marefat, F. (2006). Student writing, personality type of the student and the rater: Any interrelationship?. Reading Matrix: An International Online Journal, 6(2), 116-124.

Myers, I. B., \& Briggs, K. C. (1998). Myers- Briggs Type Indicator. STEP I/Self- Scorable, Form M. Palo Alto, CA: Consulting Psychologists Press.

Oshima, A. And Hogue. 1999. Writing Academic English; Third Edition. United State of America: Addison Wesley Publishing Company.

Prasad, T. (2012). A Course in Linguistics. Second Edition. New Delhi: PHI Learning.

Robertson, I. T. (1985). Human information-processing strategies and style. Behavior and Information Technology, 4(1), 19-29. http://dx.doi.org/10.1080/01449298508901784.

Sanjaya, D., Mokhtar, A.A., \& Sumarsih (2015). The Impact of Personality (Extroversion/Introversion) on Indonesian EFL Learners' Essay Writing Achievement. Asian EFL Journal. 87 (10), 4-19.

Sharples, M. 1999. How We Write; Writing as Creative Design. London: Routledge.

Tennant, M. (1988). Psychology and adult learning. London: Routledge. http://dx.doi.org/10.4324/9780203441619.

Vaezi, S., (2012). Learner characteristics and syntactic and lexical complexity of written products. International Journal of Linguistics, 4(3), 671-687.

Wakamoto, N. (2007). Language learning strategy and personality variables: Focusing on extroversion and introversion. IRAL. International review of applied linguistics in language teaching, 38(1), 71-81.

Witkin, H. A., \& Goodenough, R. D. (1981). Cognitive styles: Essence and origin. New York: International University Press.

Zainuddin, Z. (2016). The Impact of Personality: Extrovert vs. Introvert on the Ability in Syntax in Essay Writing. Studies in English Language and Education, 3(2), 158-169. 